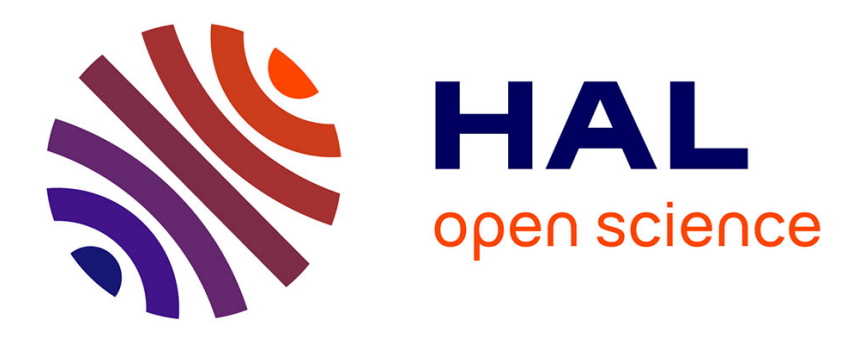

\title{
Aerosol Therapy for Pneumonia in the Intensive Care Unit
}

Charles-Edouard Luyt, Guillaume Hekimian, Nicolas Brechot, Jean Chastre

\section{To cite this version:}

Charles-Edouard Luyt, Guillaume Hekimian, Nicolas Brechot, Jean Chastre. Aerosol Therapy for Pneumonia in the Intensive Care Unit. Clinics in Chest Medicine, 2018, 39 (4), pp.823 - 836. 10.1016/j.ccm.2018.08.005 . hal-01924707

\section{HAL Id: hal-01924707 https: / hal.sorbonne-universite.fr/hal-01924707}

Submitted on 17 Dec 2018

HAL is a multi-disciplinary open access archive for the deposit and dissemination of scientific research documents, whether they are published or not. The documents may come from teaching and research institutions in France or abroad, or from public or private research centers.
L'archive ouverte pluridisciplinaire HAL, est destinée au dépôt et à la diffusion de documents scientifiques de niveau recherche, publiés ou non, émanant des établissements d'enseignement et de recherche français ou étrangers, des laboratoires publics ou privés. 


\section{Aerosol Therapy for Pneumonia in the Intensive Care Unit}

Charles-Edouard Luyt, MD, PhDa , Guillaume Hékimian, $\mathrm{MD}^{\mathrm{a}}$, Nicolas Bréchot, MD, PhD ${ }^{a}$, Jean Chastre, $\mathrm{MD}^{\mathrm{a}, \mathrm{b}, *}$

\section{KEYWORDS}

- Ventilator-associated pneumonia • Aerosol • Amikacin • Colistin

\section{KEY POINTS}

- Aerosol antibiotic administration may allow achieving very high drug concentrations at the infection site in the lung, with low systemic absorption.

- However, optimal deposition in the tracheobronchial tree and alveolar compartment requires specific devices, drug formulations and ventilator settings, with close clinical monitoring.

- To date, antibiotic aerosolization in adults with pneumonia can only be recommended when the infection is caused by extensively resistant pathogens only susceptible to antibiotics with limited efficacy and high toxicity when given by the IV route (ie, aminoglycosides and colistin).

\section{INTRODUCTION}

Hospital-acquired pneumonia (HAP), including ventilator-associated pneumonia (VAP), is still a common intensive care unit (ICU) infection, with a high attributable morbidity and mortality. With current standard-of-care therapy, clinical success rates are often less than $60 \%$, related to the many challenges that encompass antibiotic therapy in critically ill patients, including alterations in pharmacokinetics (PK) and pharmacodynamics (PD), relative low penetration of most antibiotics into the lung tissue, and the frequency of difficult-to-treat or highly resistant pathogens in that setting.

Aerosol antibiotic administration offers the theoretic advantages of achieving high drug concentrations at the infection site, considerably more than the minimal inhibitory concentration (MIC) of most causative microorganisms, and low systemic absorption, thereby avoiding toxicity, particularly the renal toxicity of aminoglycosides or colistin. The poor development of this potentially advantageous technique in patients on mechanical ventilation (MV) is caused partly by high amounts of the particles dispersed by conventional nebulizers depositing in the ventilatory circuits and the tracheobronchial tree during $\mathrm{MV}$, therefore not reaching the distal lung, and hence less drug is available in the alveolar compartment. Current nonstandardized clinical practice, the difficulties of implementing optimal nebulization technique, and lack of robust clinical data

Conflicts of Interest: J. Chastre and C.-E. Luyt have received honoraria from Bayer HealthCare for having participated in advisory boards on nebulized amikacin, and are investigators of Inhale 2, a phase 3 study on nebulized amikacin using the PDDS Clinical device in patients with gram-negative pneumonia, sponsored by Bayer HealthCare.

a Service de Réanimation Médicale, Institut de Cardiologie, Groupe Hospitalier Pitié-Salpêtrière, Assistance Publique-Hôpitaux de Paris, 47-83 Boulevard de I'Hôpital, Paris Cedex 13 75651, France; ${ }^{\text {b }}$ Sorbonne Universités, UPMC Université Paris 06, INSERM, UMRS_1166-ICAN Institute of Cardiometabolism and Nutrition, Paris, France

* Corresponding author. Service de Réanimation Médicale, Institut de Cardiologie, Groupe Hospitalier PitiéSalpêtrière, Assistance Publique-Hôpitaux de Paris, 47-83 Boulevard de l'Hôpital, Paris Cedex 13 75651, France. E-mail address: jean.chastre@aphp.fr 
considerably limit widespread adoption. However, with the recent development of new nebulizers, ${ }^{2-6}$ antibiotic aerosolization in patients with pneumonia has renewed interest. ${ }^{7-9}$ This article focuses on patients with VAP.

\section{RATIONALE FOR THE USE OF INHALED ANTIBIOTICS IN MECHANICALLY VENTILATED PATIENTS}

Effective antimicrobial therapy requires adequate drug concentrations at the target site of infection, which is often not possible when using conventional intravenous (IV) therapy in ICU patients requiring $\mathrm{MV}$ because of the poor lung tissue penetration of many antimicrobial agents and the unpredictable modifications observed in their pharmacokinetics. ${ }^{10-14}$ For many drugs, significant increases in the volume of distribution and/ or variability in clearance are observed in the most severe ICU patients. When standard doses are used, such pharmacokinetic changes can result in subtherapeutic plasma concentrations, treatment failure, and the development of antibiotic resistance. Thus, even when the microorganism is susceptible to currently available antibiotics, the outcome is frequently suboptimal with a high rate of failure and/or relapse. This suboptimal outcome is particularly problematic when the microorganism responsible for infection has an MIC very close to the breakpoint defining the potential efficacy of these antibiotics, as is more and more frequently encountered nowadays in many countries. To treat these strains, raising the dose of systemic antibiotics and/or modifying the modalities of administration (ie, using continuous infusion) are the only options, but it can be responsible for an increased toxicity and lead to acute renal failure and/or neurologic complications. $^{15}$

Inhalation therapy has the capability of directly targeting the airways, creating increased and more sustained local concentrations and thereby increasing the therapeutic index, improving efficacy, and minimizing toxicities. Although never shown, the microflora of the gut is probably less altered with nebulized antibiotics than with systemic antibiotics, which might also decrease the emergence and dissemination of resistant strains, including Clostridium difficile.

However, many clinicians do not fully appreciate the complexities associated with inhaled therapy, in part because of misconceptions based on inadequate techniques performed in the past, including instilling antibiotic solutions through the endotracheal tube and using existing parenteral formulations for inhalation. ${ }^{16}$

\section{HOW TO OPTIMIZE LUNG DELIVERY OF ANTIBIOTICS DURING AEROSOLIZATION}

One of the main limitations of nebulization is that a part of the nebulized drug is trapped in the ventilator circuit and the upper airways by impaction. ${ }^{17}$ This impaction of aerosol droplets is driven by the size of particles but also by the turbulences generated in the gas flow. Several factors can influence nebulization efficiency: the generator, the size of the particles (which are largely dependent of the generator), the ventilator settings and circuit, the drug (dose, formulation), and the patients themselves. Although the patients are an unchangeable factor, other factors can be modified to increase the nebulization efficiency (Fig. 1). ${ }^{18}$

\section{The Aerosol Generator}

There are 3 types of nebulizers: jet, ultrasonic, and vibrating-mesh or plate nebulizers. ${ }^{3,7}$ Table 1 shows the potential advantages and drawbacks of the 3 types of nebulizers.

The generation of aerosol with jet nebulizers uses air or oxygen under high pressure. The gas may come either from a wall system (the generated flow is continuous, during the inspiratory and expiratory phases), or from the ventilator (the device is connected to the ventilator and the driving pressure is provided by the ventilator itself, delivering an intermittent flow during the inspiratory phase). With this kind of nebulizer, drug delivery into the lungs might be highly variable from one generator to another, depending on the brand, the pressure of the driving gas, and the position of the device on the ventilatory circuit. ${ }^{19}$ This variability is decreased with newer generations of ventilators, marketed with built-in nebulizers that have been tested to generate efficient aerosols during intermittent operation. ${ }^{3}$ The efficiency of jet nebulizers is increased when the connection with the inspiratory limb is at a distance from the endotracheal tube, compared with its connection between the $Y$ piece and the endotracheal tube. . $^{7,20,21}$

Ultrasonic nebulizers use the vibration of a piezoelectric crystal to produce the aerosol. The aerosol particle size is inversely proportional to the piezoelectric crystal vibration frequency, and drug output is directly proportional to the amplitude of crystal vibration. ${ }^{2}$ The main advantages of this technique are the short time of nebulization and the high flow of nebulization. ${ }^{2,22}$ However, the use of these devices may increase the temperature of the solution by $10^{\circ} \mathrm{C}$ to $15^{\circ} \mathrm{C}$ after a few minutes of ultrasonic nebulization, which can lead to antibiotic denaturation and inactivation. ${ }^{2,23}$ Moreover, the drug solution becomes 

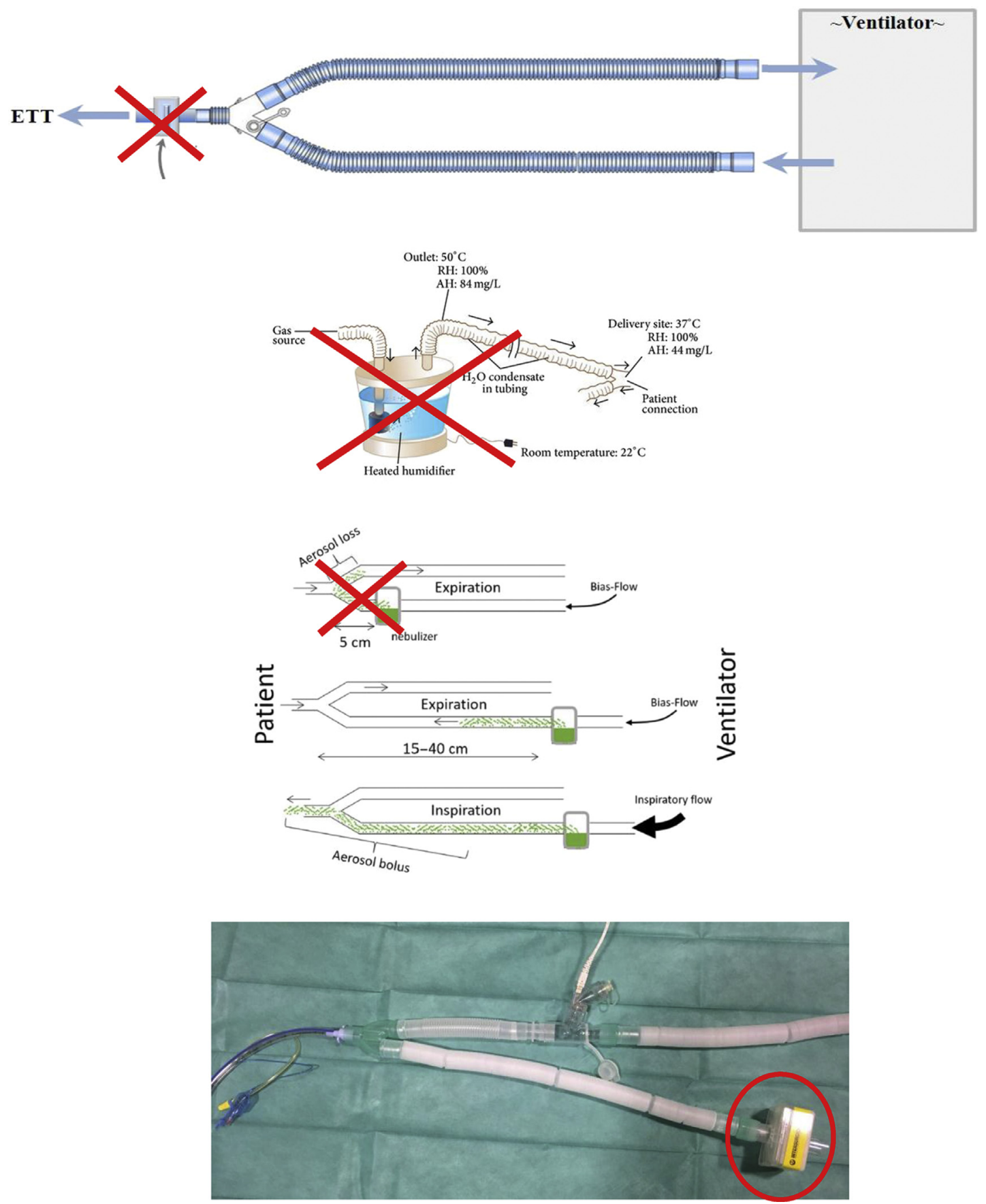

Fig. 1. Four key practices for optimal antibiotic nebulization during MV. (1) No filter should be placed between the nebulizer and the endotracheal prosthesis. (2) If a heated humidifier was used for humidifying and warming the inspiratory gases delivered by the mechanical ventilator, it should be switched off during aerosolization. (3) At best, vibrating-mesh nebulizers have to be placed on the inspiratory limb of the ventilator, 10 to $40 \mathrm{~cm}$ from the $Y$ piece. To decrease impaction, the $Y$ piece should have no acute or right angles, and should be connected directly to the endotracheal tube. (4) A filter (red circle) should be placed on the expiratory limb of the circuit to avoid antibiotic nebulization in the environment. This filter has to be replaced after each nebulization. 


\begin{tabular}{|c|c|c|}
\hline & Advantages & Drawbacks \\
\hline Jet nebulizer & $\begin{array}{l}\text { Low cost } \\
\text { Unique use } \\
\text { Can be breath synchronized }\end{array}$ & $\begin{array}{l}\text { Variable size of particles } \\
\text { Long duration of nebulization } \\
\text { Lower efficiency } \\
\text { High performance variability } \\
\text { High residual volume of drug } \\
\text { Potential interference with the tidal volume } \\
\text { delivered by the ventilator }\end{array}$ \\
\hline Ultrasonic nebulizer & $\begin{array}{l}\text { High efficiency } \\
\text { High speed of drug delivery } \\
\text { Easy to use } \\
\text { Low residual volume of drug }\end{array}$ & $\begin{array}{l}\text { High cost } \\
\text { Increase in the solution temperature, which } \\
\text { can degrade heat-sensitive drugs } \\
\text { Hygiene concern } \\
\text { No breath synchronization }\end{array}$ \\
\hline $\begin{array}{l}\text { Vibrating-mesh } \\
\text { nebulizer }\end{array}$ & $\begin{array}{l}\text { Small particle size, precisely } \\
\text { calibrated } \\
\text { Very high efficiency } \\
\text { Easy to use } \\
\text { Low residual volume of drug }\end{array}$ & $\begin{array}{l}\text { High cost } \\
\text { No breath synchronization } \\
\text { Low efficacy with viscous solutions }\end{array}$ \\
\hline
\end{tabular}

more concentrated during operation. Whether or not increase in temperature and concentration of the drug can lead to antibiotic inactivation remains to be determined for each molecule to be used.

Although they are more efficient than jet nebulizers, ${ }^{22,24}$ they are not widely used, mostly because of their cost and potential drawbacks.

Vibrating-mesh nebulizers are a newer generation of nebulizers. The nebulizer/reservoir unit comprises the aerosol generator and a drug reservoir. The aerosol is generated by the vibration of a plate with uniform holes. This vibration creates a rapid pumping of liquid droplets through the holes, thereby producing the aerosol. The size of the droplets depends directly on the diameter of the tapered holes, and can vary from 1 to $5 \mu \mathrm{m}$. The nebulizer/reservoir unit is connected to the ventilator circuit through a T-piece adapter placed on the inspiratory limb of the circuit. Unlike ultrasonic nebulizers, the temperature of the solution does not change during operation of the vibrating-mesh nebulizers, and drugs can be nebulized with minimal risk of denaturation. The vibrating-mesh nebulizers have many advantages compared with jet nebulizers, as indicated in Table 1 , but they are costly. ${ }^{7}$

\section{Size of the Particles}

During MV, part of the aerosol is trapped in the ventilator circuit and the endotracheal tube. ${ }^{21}$ Large droplets $(>3 \mu \mathrm{m})$ are more likely to affect the circuit, whereas smaller particles $(<0.5 \mu \mathrm{m})$ diffuse and are more likely to be expelled during expiration. ${ }^{21,25,26}$
Consequently, the optimal size of the generated particles to achieve the best alveolar deposition is between 1 and $3 \mu \mathrm{m}$. The size of the particles depends on the aerosol generator and its settings: on jet nebulizers, droplet size decreases when gas flow increases, whereas droplet size increases with increase in the ratio of liquid to gas flow. On ultrasonic nebulizers, aerosol particle size is inversely proportional to the piezoelectric crystal vibration frequency, and drug output is directly proportional to the amplitude of crystal vibration. On vibrating-mesh nebulizers, droplet size is homogeneous and can be precisely calibrated. ${ }^{7,19,25,26}$

\section{Ventilator Settings}

Ventilator settings are of importance for improving lung deposition. Indeed, any turbulence in inspiratory flow may cause an increase in impaction and deposition of droplets that leads to decreased lung drug deposition. Air turbulence can be decreased by optimizing ventilator settings: the best ventilator mode is volume-controlled mode (compared with pressure-controlled mode) with a constant inspiratory flow. ${ }^{27}$ The tidal volume is also important, because a high tidal volume is associated with a better lung deposition. Experts recommend a Vt of $8 \mathrm{~mL} / \mathrm{kg},{ }^{28,29}$ with a long inspiratory time (which can be obtained by increasing the $1 / E$ ratio). ${ }^{30,31}$ A low inspiratory flow achieves better lung deposition than a high flow. Consequently, the authors recommend setting the inspiratory flow at $40 \mathrm{~L} / \mathrm{min}^{28,31,32}$ whenever possible, because it can be poorly supported by the patient, and requesting increasing sedation. 


\section{Ventilator Circuit}

Aerosol impaction on the respiratory circuit and the tracheal tube is a limitation of nebulization. Impaction (and thus aerosol lung deposition) is modified by the position of the nebulizer. Heated humidity decreases the amount of delivered drug by increasing the size of the droplets. ${ }^{4,19,33}$ When using a heat/moisture exchanger, this has to be repositioned at the end of the expiratory circuit during nebulization (to avoid contamination of the environment by the product) and replaced at the end of the session (to avoid obstruction of the filter and thus of the expiratory circuit). ${ }^{4,19}$ When using a heated humidifier, it should be switched off during nebulization, or the amount of drug should be increased. ${ }^{4,19}$

It has recently been shown, in an experimental study, that jet nebulizers provide the highest efficiency when placed proximal to the ventilator. ${ }^{33}$ For ultrasonic nebulizers, the distal or proximal placement in the ventilator circuit had no impact on its efficiency. ${ }^{24}$ However, in a recent experimental study on a dual-chamber test lung using an ultrasonic nebulizer, the investigators compared the deposition of albuterol according to its position. ${ }^{33}$ The highest lung deposition was obtained when the nebulizer was placed 15 to $40 \mathrm{~cm}$ from the $Y$ piece in the inspiratory limb. Other positions of the nebulizer on the circuit (between the $Y$ piece and the endotracheal tube, on the inspiratory limb of the circuit at $15 \mathrm{~cm}$ from the ventilator) were associated with less efficiency. Heated/humidified and nonhumidified conditions did not change the deposition of albuterol. ${ }^{33}$

Few data are available for vibrating-mesh nebulizers. Experts recommend the placement of the device in the inspiratory limb of the circuit, 15 to $40 \mathrm{~cm}$ from the $Y$ piece (see Fig. 1). In an experimental study, Ari and colleagues ${ }^{33}$ showed that, during simulated adult $\mathrm{MV}$, placement of a vibrating-mesh nebulizer in the inspiratory limb $15 \mathrm{~cm}$ from the $Y$ piece provided the best deposition, compared with other places, which has recently been confirmed in another in vitro study. ${ }^{31}$

A new system not currently marketed, the Amikacin Inhale vibrating-mesh nebulizer, was recently developed by Aerogen/Bayer in an on-ventilator configuration for intubated and mechanically ventilated patients and in a handheld configuration for patients who are not intubated. The latter allows patients to continue treatment if extubated during the course of therapy. Several design features of Amikacin Inhale offer improvements compared with other aerosol generators for mechanically ventilated patients: it generates particles with a consistent mean size of 2.9 to
3.3 $\mu \mathrm{m}$, suitable for deposition throughout the lower airway; it is synchronized with the ventilator in order to deliver nebulization during the first $75 \%$ of the patient's inspiratory cycle; it does not request modifying the ventilatory setting; it does not require patient sedation or changes in the inspiratory to expiratory cycle ratio or other ventilator changes needed to improve deposition with generic devices; and it has a high in vitro delivery efficiency of $\sim 50 \%$, which is unaffected by circuit humidification. $^{8,9,28}$

\section{AEROSOLIZATION DRAWBACKS}

Although antibiotic nebulization seems attractive, it has several drawbacks and some questions have not yet been resolved.

\section{Adverse Effects of Antibiotic Nebulization}

In addition to the effects of the systematically absorbed antibiotic (ie, renal toxicity for aminoglycosides and polymyxins), most adverse events result from the direct toxicity on airways and lung parenchyma (mucosal irritation). Cough and a disagreeable taste, which are minor and transient, are frequently reported. ${ }^{34}$ Bronchospasm is a more severe, but less common, side effect that has been described in patients receiving nebulized antibiotic, especially when the IV formulation was used. Bronchospasm during aerosolization imposes the immediate withdrawal of the aerosol and $\beta$-agonist nebulization. ${ }^{28,34-36}$ In case of bronchospasm occurring during antibiotic nebulization, reintroduction of the same drug by the same route should be avoided. One of the most dreadful complications of antibiotic nebulization is the obstruction of the expiratory filter, which can lead to cardiac arrest and death, as reported by Lu and colleagues. ${ }^{37}$ This complication can be avoided by a systematic change of the expiratory filter after each aerosol.

\section{Parenchymal Lung Penetration}

In healthy humans, nebulized antibiotic penetration into lung tissues is good. ${ }^{38}$ However, in patients with alveolar consolidations, it is less certain. Most studies evaluating aerosolized antibiotics in patients with VAP found high antibiotic levels in tracheal aspirates, ${ }^{34,39}$ but high sputum antibiotic levels do not necessarily mean high levels at the infection site (ie, in the lung parenchyma). In piglets with experimental pneumonia, Goldstein and colleagues ${ }^{40}$ found that amikacin penetration into the lung was less in consolidated areas than in well-aerated alveoli, but greater than with IV administration. In humans, Luyt and 
colleagues $^{35,36}$ found that administering aerosolized amikacin to patients with gram-negative VAP achieved very high aminoglycoside concentrations in epithelial lining fluids (ELFs) and VAPaffected lung zones while maintaining safe serum drug concentrations. Those ELF concentrations were always greater than the antibiotic's MIC for gram-negative microorganisms usually responsible for VAP.

\section{Emergence of Resistant Strains}

Two studies looked for the emergence of resistant strains in proximal airways' respiratory secretions among chronically ill patients who received an adjunctive inhaled antibiotic. ${ }^{41,42}$ Aerosolized antibiotics successfully eradicated existing multidrugresistant (MDR) microorganisms and reduced the pressure from systemic agents for new respiratory resistance. However, no prolonged surveillance of patients included in these studies was performed, raising some doubt about the true efficacy of such a strategy, because the on-going use of antibiotics at subtherapeutic levels outside the respiratory tract, particularly at the level of the digestive tract, may lead to selection of antibiotic-resistant organisms. ${ }^{43}$ Thus, as for all prevention and/or therapeutic strategies based on the use of antimicrobial agents, antibiotic nebulization must be managed prudently, particularly concerning treatment duration, which should be kept as short as possible. ${ }^{44,45}$

\section{Prolonged Duration of Aerosolization}

Another limitation of antibiotic aerosolization is the long aerosolization time required in some situations, which could lead to the prolongation of MV and ICU stay. Indeed, to be more efficient, antibiotic aerosolization must be accompanied by specific ventilator settings (discussed earlier). However, decreasing the inspiratory flow may increase patient discomfort. For many patients, physicians need to increase or start sedation to maintain patients who are perfectly adapted to their ventilators, which might lead to MV prolongation. As an example, in their study comparing aerosol therapy with the IV route for Pseudomonas aeruginosa VAP, Lu and colleagues ${ }^{37}$ found that duration of MV and ICU stay after randomization were longer (although not statistically significant) in patients receiving aerosols, probably in part because of the need for an increased sedation level.

\section{Cost}

Most of the devices, especially the latest generations of vibrating-mesh nebulizer, are expensive.
Moreover, to be nebulized, a special antibiotic formulation must be prepared, which can also be costly. In addition, most companies developed antibiotic formulations to be administered via a specific device, thereby further increasing the cost of delivery by nebulization. ${ }^{34}$

\section{Legal Concerns}

Inhaled drug formulation considerations are extremely important when considering administering inhaled antimicrobial therapy to a patient with a bacterial pneumonia. Only drugs prepared and manufactured specifically for inhalation should be used. They should be pyrogen free; isotonic; sterile; $\mathrm{pH}$ balanced to the airway epithelium ( $\mathrm{pH} 6)$; and dispensed in unit-dose, single-use containers. Importantly, preservatives and sulfites should be avoided if possible, because they have been specifically associated with adverse effects when inhaled.

Most antibiotics have only been approved for IV use and not for direct delivery to the lungs. A special formulation for nebulization exists in France for colistin and tobramycin, but the use of other antibiotics is off label. ${ }^{28,34}$ The situation is the same in most European countries and the United States, and it may have legal issues. It should also be noted that there is very limited information regarding the doses that should be used when aerosolizing antibiotics (discussed later).

\section{EXPERIMENTAL DATA SUPPORTING THE USE OF ANTIBIOTIC AEROSOLIZATION}

Several studies in animal models of VAP have shown that antibiotic aerosolization led to higher antibiotic concentration into the lung than IV infusion. From a pharmacodynamic point of view, aminoglycosides and colistin are concentrationdependent antibiotics with a postantibiotic effect. They are particularly suitable for nebulization because high lung concentrations can be expected and only 1 to 3 daily administrations are required. Time-dependent antibiotics, like $\beta$-lactams or glycopeptides, require that drug concentrations be maintained at more than the MIC throughout the dosing interval. Continuous or closely repeated administration is hence required, which could limit the clinical feasibility of nebulized delivery of such drugs.

In healthy piglets, Goldstein and colleagues ${ }^{46}$ compared amikacin lung tissue concentrations after nebulization with those after IV administration. The lung concentrations of amikacin were more than 10-fold higher after nebulization than the lung concentrations after IV administration, and were homogeneously distributed throughout the 
lung parenchyma. These concentrations were far in excess of the MIC of most gram-negative strains responsible for VAP. These data were confirmed in piglets with experimental pneumonia caused by Escherichia coli: the amikacin lung concentration was 3-fold to 30-fold higher after nebulization than after IV administration. ${ }^{40}$ In the lungs of piglets having received nebulized amikacin, amikacin concentrations were lower in the infected (consolidated) segments of the lungs than in the nonconsolidated, noninfected parts of the lungs, but even in the infected parenchyma it was higher than the concentration achieved with IV amikacin. Moreover, bactericidal efficacy seemed better after nebulization than after IV administration, the lung bacterial burden being significantly lower in the lungs of animals receiving aerosolized amikacin than in the lungs of animals receiving IV amikacin. ${ }^{40}$

Recently, the same team evaluated lung deposition of colistin administered intravenously or via a vibrating-mesh nebulizer in piglets. Colistin was not detected in lung tissue following IV infusion, whereas it was detected in the lung parenchyma of animals receiving nebulized colistin, with peak lung tissue concentrations greater in lung segments with mild pneumonia than in lung segments with severe pneumonia. ${ }^{47}$ Accordingly, bacterial burden in the lungs of aerosol-treated animals was lower than in the lung of IV-treated animals. ${ }^{47}$

In humans, lung penetration of aerosolized antibiotics (at least for aminoglycosides and colistin) seems better than when using the IV route: in 1993, Le Conte and colleagues ${ }^{48}$ found that a single nebulization of tobramycin in healthy subjects led to high lung parenchymal concentrations with low serum level. These results were recently confirmed by Niederman and colleagues ${ }^{49}$ in a pharmacokinetic study of nebulized amikacin using the breath-synchronized vibrating-mesh nebulizer developed by Aerogen/Bayer in ventilated patients with microbiologically confirmed gramnegative pneumonia. Two other pharmacokinetic studies using bronchoalveolar lavage for assessing amikacin penetration into the alveolar ELF found high amikacin concentrations from infected alveolar spaces, whereas serum amikacin concentration remained low, less than the toxicity level, in patients with or without acute renal failure. ${ }^{35,36}$

There are no recommended doses for colistin or aminoglycoside nebulization. In patients with VAP or ventilator-associated tracheobronchitis (VAT) who were administered 1 million international units (MIU, ie, $80 \mathrm{mg}$ ) of colistimethate sodium (CMS), the precursor of colistin, via a vibrating-mesh nebulizer every 8 hours, peak ELF concentrations were high but then decreased to less than the sensitivity breakpoint at 4 hours, thus indicating that this dose may not be optimal for treating. ${ }^{50}$ Steady-state plasma concentrations of colistin, indirectly reflecting alveolar deposition, were significantly higher in studies evaluating high doses of nebulized CMS (4-5 MIU/8 h $)^{46,47}$ compared with 2 MIU/8 h. ${ }^{51}$ In the largest retrospective study published to date, the investigators gave $300 \mathrm{mg}$ of tobramycin twice daily or $1000 \mathrm{mg}$ of amikacin twice daily. ${ }^{52}$ Palmer and colleagues ${ }^{41}$ administered $80 \mathrm{mg}$ of gentamicin every 8 hours in patients with ventilator-associated tracheobronchitis. In the most recent studies that used a breath-synchronized vibrating-mesh nebulizer, $400 \mathrm{mg}$ of amikacin twice daily allowed high tracheal and ELF levels. ${ }^{35,36}$ Using nebulizers to administer aminoglycosides allows reducing the dose of aminoglycosides compared with IV doses, ${ }^{41,52}$ but the exact amount of aminoglycosides to be nebulized remains to be determined and depends on the device used.

Taken together, these results suggest that nebulization of antibiotics can effectively deliver antibiotics in higher concentrations to the lungs of patients with pneumonia than the IV route.

\section{ANTIBIOTIC AEROSOLIZATION: FOR WHOM AND WITH WHAT EFFICACY?}

Aerosolized antibiotics can be used either as an adjunctive therapy to standard IV antibiotics, instead of IV antibiotics, or in patients with pneumonia caused by extensively drug-resistant (XDR) pathogens for which no IV therapy is readily available.

\section{Aerosolization as an Adjunctive Treatment to Active Intravenous Antibiotics}

In this setting, aerosol antibiotic administration is associated with IV antibiotics active against the pathogen responsible for pneumonia, with the aim of increasing efficiency, accelerating clinical and bacteriologic cure, and improving outcome. However, practically all studies performed to date showed no improvement in clinically relevant outcomes when comparing aerosolized antibiotics with aerosolized placebo.

In a randomized, placebo-controlled, doubleblind study, Rattanaumpawan and colleagues ${ }^{53}$ evaluated patients with gram-negative VAP having received either nebulized colistin $(n=51)$ or nebulized placebo $(n=49)$ in addition to IV antibiotics. Clinical outcomes including clinical cure, mortality, and VAP-attributed mortality were similar in the two groups, whereas microbiological cure rate was higher in patients receiving nebulized colistin than in those receiving placebo. Complications 
were similar in the two groups. ${ }^{53}$ Using a breathsynchronized vibrating-mesh nebulizer, the PDDS Clinical, Niederman and colleagues ${ }^{49}$ randomized 69 mechanically ventilated patients with gram-negative VAP to receive 7 to 14 days of aerosolized amikacin $400 \mathrm{mg}$ twice a day $(n=21)$, amikacin $400 \mathrm{mg}$ once daily and placebo 12 hours later $(n=26)$, or placebo twice a day $(n=22)$ (33) in addition to IV antimicrobials. Aerosolized amikacin was well tolerated, without any severe adverse event, and patients who received amikacin twice daily required significantly less antibiotic than patients receiving nebulized placebo (mean number of systemic antibiotics per patient per day at the end of treatment, 0.9 vs 1.9 , respectively; $P=.02$ ), perhaps because their disease improved more rapidly, but no other benefit could be shown.

Results of 2 large, double-blind, placebocontrolled, randomized trials were recently made available. In the first, the investigators compared standard of care in each arm plus $300 \mathrm{mg}$ amika$\mathrm{cin} / 120 \mathrm{mg}$ fosfomycin or placebo (saline), delivered by aerosol twice daily for 10 days via an efficient mesh-vibrating nebulizer, the PARI eFlow. ${ }^{54}$ A total of 143 patients with gramnegative bacterial VAP were studied. Comparison of Clinical Pulmonary Infection Score change from baseline between treatment groups was not different, as well as the secondary hierarchical end point of no mortality and clinical cure at day 14. Patients randomized in the amikacin/fosfomycin nebulized group had significantly fewer positive tracheal cultures within the 7 days following randomization, but the relevance of such an end point is doubtful because of the presence of high antibiotic concentrations in respiratory secretions obtained from patients having received aerosolized antibiotics, which could have rendered falsely negative culture results. ${ }^{54}$

The second study, not yet published, was the Bayer Inhaled study, a multicenter, randomized, placebo-controlled, double-blind trial that investigated the clinical efficacy and safety of adjunctive nebulized amikacin compared with standard care and nebulized placebo for the treatment of gramnegative pneumonia in adult ICU ventilated patients (phase III study program with Amikacin Inhale in addition to standard of care in intubated and mechanically ventilated patients with gramnegative pneumonia does not meet primary end point of superiority. News release: Friday, November 24, 2017. http://press.bayer.com/ baynews/baynews.nsf/id/Phase-III-study-programAmikacin-Inhale-addition-standard-intubated-me chanically-ventilated-patients). The primary outcome measure was survival at day 30 .
Secondary outcome measures included pneumonia-related mortality to day 30 , early clinical response up to day 10 , number of days on $\mathrm{MV}$, and number of ICU days up to day 30. Seven-hundred and twenty-five eligible patients were randomized into 2 arms. Patients in the first arm received $400 \mathrm{mg}$ of a specially formulated Amikacin Inhalation Solution every 12 hours for 10 days administered using the Synchronized Inhalation System, a mesh-vibrating nebulizer synchronized with inspiration. Patients in the comparator arm received aerosolized placebo every 12 hours for 10 days, also administered using the Synchronized Inhalation System. Both groups received standard-of-care IV antibiotics following American Thoracic Society (ATS) guidelines or local guidelines. The primary end point (overall mortality at day 28), as well as secondary end points, were similar in both treatment arms, and therefore the study failed to show he superiority of adjunctive aerosolized amikacin versus standard of care.

Based on these results and data obtained from previous trials, the use of aerosolized antibiotics as an adjunctive treatment to IV antibiotics active against the pathogen responsible for pneumonia cannot be recommended. ${ }^{55-60}$

\section{Aerosolized Antibiotics Used Alone, Instead of Intravenous Antibiotics}

Nebulization of antibiotics offers the possibility of delivering very high lung tissue concentrations of antibiotics in normal and infected lungs with rapid bacterial killing, as documented in experimental studies. ${ }^{40}$ As such, it can provide similar efficiency in terms of clinical cure of VAP caused by susceptible microorganisms, while not using potentially toxic IV antibiotics. The feasibility and clinical utility of such a strategy was assessed in a randomized controlled trial that included 40 patients with VAP caused by $P$ aeruginosa. ${ }^{37}$ Twenty patients infected with susceptible or intermediate strains received nebulized ceftazidime and amikacin. Seventeen patients infected with susceptible strains received IV ceftazidime by continuous administration and amikacin. In 3 patients infected with intermediate strains, amikacin was replaced by ciprofloxacin. After 8 days of antibiotic administration, aerosol and IV groups were similar in terms of successful treatment ( $70 \%$ vs $55 \%)$, treatment failure (15\% vs $30 \%)$, and superinfection with other microorganisms (15\% vs $15 \%)$. Acquisition of per-treatment antibiotic-resistant strains was observed exclusively in the IV group. However, patients allocated to the aerosol arm required prolonged aerosolization over a total of 8 to $9 \mathrm{~h} /$ $\mathrm{d}$ and increased sedation, which might have 
contributed to MV prolongation. Indeed, although not significant, the median duration of MV after randomization was longer in the aerosol arm than in the IV arm (14 vs 8 days, $P=$ nonsignificant). ${ }^{37}$ Patients with positive blood cultures $(10 \%$ of patients with $\mathrm{VAP}^{61}$ ) are not eligible to such a strategy. Therefore, whether such a strategy can be recommended in patients with VAP is highly doubtful.

Aside from investigating curative nebulized antibiotics to treat patients with VAT and/or VAP, some investigators have also tested nebulized colistin, ceftazidime, or aminoglycosides for prophylaxis in intubated patients. Two small studies obtained positive results with such a preemptive inhaled therapy in terms of VAP incidence, with no significant change in the bacterial antibiotic sensitivity pattern. ${ }^{58,62}$ Further studies are required to assess this benefit as well as the risk of antibiotic resistance selection pressure.

\section{Patients with Pneumonia Caused by Extensively Drug-Resistant Pathogens}

Adjunctive aerosolization of still-active antibiotics (namely colistin and aminoglycosides) seems a logical step in patients with pneumonia caused by XDR pathogens only susceptible to these drugs. Because of their systemic toxicity, it is difficult to use them intravenously at an optimized PK/ PD dosing, and thus, aerosolization seems to be the best way to achieve the high drug concentrations that are required at the site of infection for maximal bacterial killing while avoiding nephrotoxicity.

Czosnowski and colleagues ${ }^{52}$ evaluated 49 patients who received aerosolized antibiotics for the treatment of a total of 60 episodes of VAP caused by $P$ aeruginosa and/or Acinetobacter baumannii. Investigators used nebulized tobramycin, amikacin, and colistimethate in 44, 9, and 9 episodes, respectively. Systemic antibiotics were used in all except 1 patient. The main outcome measure was clinical success, which was achieved in $36(73 \%)$ of the 49 first episodes of VAP, $8(73 \%)$ of 11 subsequent episodes, 17 $(85 \%)$ of 20 episodes that were failing IV monotherapy, and $30(79 \%)$ of 38 episodes with MDR $P$ aeruginosa or $A$ baumannii. Microbiologic success was achieved in 29 (71\%) of 41 evaluable episodes. ${ }^{52}$ Table 2 shows other important studies having reported patients treated with nebulized colistin. Most patients were treated with a combination of IV antibiotics in addition to nebulized colistin. In one of the most recent studies reported, the investigators compared 122 patients with $P$ aeruginosa VAP caused by sensitive strains treated with IV antibiotics with 43 patients with $P$ aeruginosa VAP caused by MDR strains that received nebulized colistin either alone ( $n=28,65 \%$ ) or in combination with a 3-day IV aminoglycoside therapy ( $n=15,35 \%)$ (36). VAP cure, VAP recurrence, and mortality were similar in patients infected with sensitive-strain $P$ aeruginosa VAP and in patients infected with MDR strains. ${ }^{63}$ None of these studies reported the emergence of colistin-resistant pathogens or renal toxicity caused by colistin nebulization. ${ }^{63-67}$ The effect of aerosolized colistin as adjunctive treatment on the outcomes of microbiologically documented VAP caused by colistin-only susceptible gram-negative bacteria was also assessed by Tumbarello and colleagues ${ }^{68}$ in a retrospective, 1:1 matched case-control study that included 208 patients. Compared with the IV-only colistin cohort, patients who received a combination of IV and aerosolized colistin had a higher clinical cure rate $(69 \%$ vs $55 \%, P=.03)$ and required fewer days of MV after VAP onset (8 days vs 12 days, $P=.001$ ). In the 166 patients with posttreatment cultures, eradication of the causative organism was also more common in the aerosolized-IV colistin group (63\% vs $50 \%$, $P=.08)$. No between-cohort differences were observed in all-cause ICU mortality or rates of acute kidney injury during colistin therapy.

Three meta-analyses were recently performed, with mixed results. ${ }^{69-71}$ Valachis and colleagues ${ }^{71}$ evaluated the efficacy and safety of aerosolized colistin as adjunctive therapy with IV antimicrobials or as monotherapy in the treatment of VAP: 16 studies were included in their meta-analysis for a total of 690 patients. A significant improvement in clinical response (odds ratio, 1.57; $P=.006$ ), microbiological eradication (odds ratio, 1.61; $P=.01$ ), and infection-related mortality (odds ratio, 0.58; $P=.04$ ) was observed with the addition of aerosolized colistin to IV treatment, whereas overall mortality was not affected (odds ratio, $0.74 ; P=.06)$, nor was nephrotoxicity (odds ratio, 1.18; $P=.45$ ). Similar results were found by Liu and colleagues ${ }^{70}$ in an analysis of 9 studies having compared a combination of IV plus nebulized polymyxin versus IV polymyxin alone in a total of 672 patients: the combination of IV plus nebulized colistin was associated with higher rates of clinical cure or improvement and pathogen eradication and lower all-cause mortality. However, in the meta-analysis done by Zampieri and colleagues, ${ }^{69}$ which included 6 randomized controlled trials for a total of 812 patients, nebulized antibiotics were not associated with microbiological cure (relative risk $(R R)=1.24$; 95\% confidence interval [Cl], 0.95-1.62), mortality 


\begin{tabular}{|c|c|c|c|c|c|c|c|c|}
\hline Author & Study Design & $\begin{array}{l}\text { Number of } \\
\text { Patients }\end{array}$ & Control Group & Pathogens & $\begin{array}{l}\text { Pathogen } \\
\text { Eradication } \\
\text { (\%) }\end{array}$ & Clinical Cure (\%) & $\begin{array}{l}\text { Time of } \\
\text { Evaluation }\end{array}$ & $\begin{array}{l}\text { Mortality } \\
(\%)\end{array}$ \\
\hline $\begin{array}{l}\text { Kwa } \\
\text { et al, }{ }^{66} \\
2005 \\
\end{array}$ & $\begin{array}{l}\text { Retrospective } \\
\text { cohort }\end{array}$ & 21 & None & $\begin{array}{l}P \text { aeruginosa } \\
A \text { baumannii }\end{array}$ & 86 & 57 & NR & 47 \\
\hline $\begin{array}{l}\text { Berlana } \\
\text { et al, }{ }^{67} \\
2005 \\
\end{array}$ & $\begin{array}{l}\text { Retrospective } \\
\text { cohort }\end{array}$ & 70 & None & $\begin{array}{l}P \text { aeruginosa } \\
A \text { baumannii }\end{array}$ & 92 & NR & NR & 18 \\
\hline $\begin{array}{l}\text { Michalopoulos } \\
\text { et al, } 65 \\
2008\end{array}$ & $\begin{array}{l}\text { Prospective } \\
\text { cohort }\end{array}$ & 80 & None & $\begin{array}{l}P \text { aeruginosa } \\
\text { A baumannii } \\
\text { Klebsiella } \\
\quad \text { pneumoniae }\end{array}$ & 83 & 83 & $\begin{array}{l}\text { End of } \\
\text { antimicrobial } \\
\text { treatment }\end{array}$ & 25 \\
\hline $\begin{array}{l}\text { Lin et al, }^{74} \\
2010\end{array}$ & $\begin{array}{l}\text { Retrospective } \\
\text { cohort }\end{array}$ & 45 & None & A baumannii & 38 & 58 & NR & 42 \\
\hline $\begin{array}{l}\text { Athanassa } \\
\text { et al, }{ }^{75} \\
2011 \\
\end{array}$ & $\begin{array}{l}\text { Retrospective } \\
\text { cohort }\end{array}$ & 12 & None & $\begin{array}{l}\text { A baumannii } \\
P \text { aeruginosa } \\
K \text { pneumoniae }\end{array}$ & 67 & 75 & NR & 25 \\
\hline $\begin{array}{l}\text { Kofteridis } \\
\text { et al, }{ }^{76} \\
2010 \\
\end{array}$ & $\begin{array}{l}\text { Retrospective } \\
\text { matched } \\
\text { cohort study }\end{array}$ & $\begin{array}{l}43 \text { patients } \\
\text { receiving IV } \\
+ \text { AS colistin } \\
\end{array}$ & $\begin{array}{l}43 \text { patients } \\
\text { receiving IV } \\
\text { colistin alone } \\
\end{array}$ & $\begin{array}{l}\text { A baumannii } \\
P \text { aeruginosa } \\
K \text { pneumoniae }\end{array}$ & $\begin{array}{l}45 \mathrm{IV}+\mathrm{AS} \\
50 \mathrm{IV} \text { alone }\end{array}$ & $\begin{array}{l}50 \mathrm{IV}+\mathrm{AS} \\
32.5 \mathrm{IV} \text { alone }\end{array}$ & $10-13 d$ & $\begin{array}{l}23 \mathrm{IV}+\mathrm{AS} \\
42 \mathrm{IV} \text { alone }\end{array}$ \\
\hline $\begin{array}{l}\text { Lu et al, }{ }^{63} \\
2012\end{array}$ & $\begin{array}{c}\text { Prospective } \\
\text { cohort }\end{array}$ & 43 & $\begin{array}{l}122 \text { patients } \\
\text { with } \\
\text { susceptible } \\
\text { strains } \\
\end{array}$ & $\begin{array}{l}P \text { aeruginosa } \\
A \text { baumannii }\end{array}$ & 69 & 67 & $14 \mathrm{~d}$ & 16 \\
\hline $\begin{array}{l}\text { Doshi et al, }{ }^{77} \\
2013\end{array}$ & $\begin{array}{l}\text { Retrospective } \\
\text { cohort study }\end{array}$ & $\begin{array}{l}44 \text { patients } \\
\text { receiving IV } \\
+ \text { AS colistin }\end{array}$ & $\begin{array}{l}51 \text { patients } \\
\text { receiving IV } \\
\text { colistin } \\
\end{array}$ & $\begin{array}{l}\text { A baumannii } \\
P \text { aeruginosa } \\
K \text { pneumoniae }\end{array}$ & $\begin{array}{l}\text { 54.5 IV + AS } \\
39.2 \mathrm{IV} \text { alone }\end{array}$ & $\begin{array}{l}\text { 44.4 IV + AS } \\
40.7 \text { IV alone }\end{array}$ & NR & $\begin{array}{l}36.4 \text { IV + AS } \\
52.9 \text { IV alone }\end{array}$ \\
\hline $\begin{array}{l}\text { Tumbarello } \\
\text { et al, }{ }^{68} \\
2013 \\
\end{array}$ & $\begin{array}{l}\text { Retrospective } \\
\text { matched } \\
\text { cohort study }\end{array}$ & $\begin{array}{l}104 \text { patients } \\
\text { receiving IV } \\
\text { + AS colistin } \\
\end{array}$ & $\begin{array}{l}104 \text { patients } \\
\text { receiving IV } \\
\text { colistin alone } \\
\end{array}$ & $\begin{array}{l}\text { A baumannii } \\
P \text { aeruginosa } \\
K \text { pneumoniae }\end{array}$ & $\begin{array}{l}63.4 \mathrm{IV}+\mathrm{AS} \\
50 \mathrm{IV} \text { alone }\end{array}$ & $\begin{array}{l}\text { 69.2 IV + AS } \\
54.8 \text { IV alone }\end{array}$ & $\begin{array}{l}\text { End of } \\
\text { antimicrobial } \\
\text { treatment }\end{array}$ & $\begin{array}{l}43 \mathrm{IV}+\mathrm{AS} \\
46 \mathrm{IV} \text { alone }\end{array}$ \\
\hline $\begin{array}{l}\text { Abdellatif } \\
\text { et al, } \\
2016\end{array}$ & $\begin{array}{l}\text { Randomized } \\
\text { controlled } \\
\text { study }\end{array}$ & $\begin{array}{l}73 \text { patients receiving } \\
\text { nebulized colistin } \\
\text { (13 had } \\
\text { monotherapy) }\end{array}$ & $\begin{array}{l}76 \text { patients } \\
\text { receiving IV } \\
\text { colistin } \\
\text { (12 had } \\
\text { monotherapy) }\end{array}$ & $\begin{array}{l}\text { A baumannii } \\
P \text { aeruginosa } \\
\text { Enterobacteriaceae }\end{array}$ & $\begin{array}{l}67.1 \text { AS } 72.3 \text { IV } \\
\text { colistin }\end{array}$ & NR & $\begin{array}{l}\text { End of } \\
\text { antimicrobial } \\
\text { treatment } \\
(14 \mathrm{~d})\end{array}$ & $\begin{array}{l}\text { 27.4 AS group } \\
23.7 \text { IV group }\end{array}$ \\
\hline
\end{tabular}


$(\mathrm{RR}=0.90 ; \mathrm{Cl} 95 \%, 0.76-1.08)$, duration of $\mathrm{MV}$ (standardized mean difference $=-0.10$ days; $95 \% \mathrm{Cl},-1.22$ to 1.00 ), ICU length of stay (standardized mean difference $=0.14$ days; $95 \% \mathrm{Cl}$, -0.46 to 0.73 ), or renal toxicity ( $R R=1.05 ; 95 \%$ $\mathrm{Cl}, 0.70-1.57)$.

\section{SUMMARY AND PERSPECTIVES}

To date, based on data reviewed earlier, antibiotic aerosolization in adults with pneumonia can only be recommended in patients with HAP/VAP caused by extensively resistant pathogens only susceptible to antibiotics with limited efficacy and high toxicity when given by the IV route (ie, aminoglycosides and colistin). Clinicians should also be aware that administration of aerosol to patients needs specific devices, drug formulations, and ventilator settings, and also close monitoring. These recommendations are consistent with existing guidelines, including those recently published by the ATS and the Infectious Diseases Society of America (IDSA). ${ }^{72}$ In the latter, experts only recommend adjunctive inhaled antibiotic therapy for patients who are most likely to benefit; specifically, those who have VAP caused by bacteria that are only susceptible to the classes of antibiotics for which evidence of efficacy by the IV alone route is the most limited (ie, aminoglycosides or colistin; weak recommendation, very low-quality evidence). However, experts from ATS-IDSA also believe that it is reasonable to consider adjunctive inhaled antibiotic therapy as a treatment of last resort for patients who are not responding to IV antibiotics alone, whether or not the infecting organism is MDR.

Careful design of future large randomized trials to turn the favorable PK/PD profile of nebulized antibiotics into improved clinical outcomes and reduced toxicity in patients with VAP is needed, with a focus on patients who can benefit the most from such a strategy (ie, those infected with very-difficult-to-treat pathogens, as indicated earlier). Defining populations at high risk of toxicity (mainly patients with acute kidney injury) may also be a worthwhile challenge. At the other end of the severity spectrum, in patients colonized by difficult-to-treat bacteria and at high risk of developing pneumonia but who do not yet show parenchymal infection, the benefits of an exclusively nebulized therapeutic strategy may warrant further evaluation. ${ }^{42,73}$

A paradigm change may occur in the future with the development of inhaled antiinfective nanoparticles, antibodies, or phage therapy, but administering aerosolized antibiotics alone to patients with VAP is premature at present and should be reserved for the specific patients for whom no other therapy is available.

\section{REFERENCES}

1. Weiss E, Essaied W, Adrie C, et al. Treatment of severe hospital-acquired and ventilator-associated pneumonia: a systematic review of inclusion and judgment criteria used in randomized controlled trials. Crit Care 2017;21(1):162.

2. Dhand R. Aerosol delivery during mechanical ventilation: from basic techniques to new devices. J Aerosol Med Pulm Drug Deliv 2008;21(1):45-60.

3. Dhand R, Guntur VP. How best to deliver aerosol medications to mechanically ventilated patients. Clin Chest Med 2008;29(2):277-96, vi.

4. Dhand R, Mercier E. Effective inhaled drug administration to mechanically ventilated patients. Expert Opin Drug Deliv 2007;4(1):47-61.

5. Waldrep JC, Berlinski A, Dhand R. Comparative analysis of methods to measure aerosols generated by a vibrating mesh nebulizer. J Aerosol Med 2007; 20(3):310-9.

6. Waldrep JC, Dhand R. Advanced nebulizer designs employing vibrating mesh/aperture plate technologies for aerosol generation. Curr Drug Deliv 2008; 5(2):114-9.

7. Luyt C-E, Combes A, Nieszkowska A, et al. Aerosolized antibiotics to treat ventilator-associated pneumonia. Curr Opin Infect Dis 2009;22(2):154-8.

8. Bassetti M, Luyt C-E, Nicolau DP, et al. Characteristics of an ideal nebulized antibiotic for the treatment of pneumonia in the intubated patient. Ann Intensive Care 2016;6(1):35.

9. Nicolau DP, Dimopoulos G, Welte T, et al. Can we improve clinical outcomes in patients with pneumonia treated with antibiotics in the intensive care unit? Expert Rev Respir Med 2016;10(8):907-18.

10. Rodvold KA, George JM, Yoo L. Penetration of antiinfective agents into pulmonary epithelial lining fluid: focus on antibacterial agents. Clin Pharmacokinet 2011;50(10):637-64.

11. Panidis D, Markantonis SL, Boutzouka E, et al. Penetration of gentamicin into the alveolar lining fluid of critically ill patients with ventilator-associated pneumonia. Chest 2005;128(2):545-52.

12. Lodise TP, Sorgel F, Melnick D, et al. Penetration of meropenem into epithelial lining fluid of patients with ventilator-associated pneumonia. Antimicrob Agents Chemother 2011;55(4):1606-10.

13. Sime FB, Roberts MS, Peake SL, et al. Does betalactam pharmacokinetic variability in critically ill patients justify therapeutic drug monitoring? a systematic review. Ann Intensive Care 2012;2(1):35.

14. Roberts JA, Abdul-Aziz MH, Lipman J, et al. Individualised antibiotic dosing for patients who are 
critically ill: challenges and potential solutions. Lancet Infect Dis 2014;14(6):498-509.

15. Schliamser SE, Cars O, Norrby SR. Neurotoxicity of beta-lactam antibiotics: predisposing factors and pathogenesis. J Antimicrob Chemother 1991;27(4): 405-25.

16. Solé-Lleonart C, Rouby J-J, Chastre J, et al. Intratracheal administration of antimicrobial agents in mechanically ventilated adults: an international survey on delivery practices and safety. Respir Care 2016;61(8):1008-14.

17. Wenzler E, Fraidenburg DR, Scardina T, et al. Inhaled antibiotics for gram-negative respiratory infections. Clin Microbiol Rev 2016;29(3):581-632.

18. Dhanani J, Fraser JF, Chan H-K, et al. Fundamentals of aerosol therapy in critical care. Crit Care 2016; 20(1):269.

19. Miller DD, Amin MM, Palmer LB, et al. Aerosol delivery and modern mechanical ventilation: in vitro/ in vivo evaluation. Am $J$ Respir Crit Care Med 2003;168(10):1205-9.

20. O'Riordan TG, Greco MJ, Perry RJ, et al. Nebulizer function during mechanical ventilation. Am Rev Respir Dis 1992; 145(5):1117-22.

21. O'Riordan TG, Palmer LB, Smaldone GC. Aerosol deposition in mechanically ventilated patients. Optimizing nebulizer delivery. Am J Respir Crit Care Med 1994;149(1):214-9.

22. Harvey CJ, O’Doherty MJ, Page CJ, et al. Comparison of jet and ultrasonic nebulizer pulmonary aerosol deposition during mechanical ventilation. Eur Respir J 1997;10(4):905-9.

23. Steckel H, Eskandar F. Factors affecting aerosol performance during nebulization with jet and ultrasonic nebulizers. Eur J Pharm Sci 2003;19(5):443-55.

24. O'Doherty MJ, Thomas SH, Page CJ, et al. Delivery of a nebulized aerosol to a lung model during mechanical ventilation. Effect of ventilator settings and nebulizer type, position, and volume of fill. Am Rev Respir Dis 1992;146(2):383-8.

25. Newman SP. How well do in vitro particle size measurements predict drug delivery in vivo? J Aerosol Med 1998;11(Suppl 1):S97-104.

26. Newman SP, Chan H-K. In vitro/in vivo comparisons in pulmonary drug delivery. J Aerosol Med Pulm Drug Deliv 2008;21(1):77-84.

27. Hess DR, Dillman C, Kacmarek RM. In vitro evaluation of aerosol bronchodilator delivery during mechanical ventilation: pressure-control vs. volume control ventilation. Intensive Care Med 2003;29(7): 1145-50.

28. Luyt C-E, Bréchot N, Combes A, et al. Delivering antibiotics to the lungs of patients with ventilatorassociated pneumonia: an update. Expert Rev Anti Infect Ther 2013;11(5):511-21.

29. Rouby J-J, Bouhemad B, Monsel A, et al. Aerosolized antibiotics for ventilator-associated pneumonia: lessons from experimental studies. Anesthesiology 2012;117(6):1364-80.

30. Fink JB, Dhand R, Grychowski J, et al. Reconciling in vitro and in vivo measurements of aerosol delivery from a metered-dose inhaler during mechanical ventilation and defining efficiency-enhancing factors. Am J Respir Crit Care Med 1999;159(1): 63-8.

31. Dugernier J, Wittebole X, Roeseler J, et al. Influence of inspiratory flow pattern and nebulizer position on aerosol delivery with a vibrating-mesh nebulizer during invasive mechanical ventilation: an in vitro analysis. J Aerosol Med Pulm Drug Deliv 2015;28(3): 229-36.

32. Dolovich MA. Influence of inspiratory flow rate, particle size, and airway caliber on aerosolized drug delivery to the lung. Respir Care 2000;45(6): 597-608.

33. Ari A, Areabi H, Fink JB. Evaluation of aerosol generator devices at 3 locations in humidified and non-humidified circuits during adult mechanical ventilation. Respir Care 2010;55(7):837-44.

34. Dhand R. The role of aerosolized antimicrobials in the treatment of ventilator-associated pneumonia. Respir Care 2007;52(7):866-84.

35. Luyt C-E, Clavel M, Guntupalli K, et al. Pharmacokinetics and lung delivery of PDDS-aerosolized amikacin (NKTR-061) in intubated and mechanically ventilated patients with nosocomial pneumonia. Crit Care 2009;13(6):R200.

36. Luyt C-E, Eldon MA, Stass H, et al. Pharmacokinetics and tolerability of amikacin administered as BAY41-6551 aerosol in mechanically ventilated patients with gram-negative pneumonia and acute renal failure. J Aerosol Med Pulm Drug Deliv 2011; 24(4):183-90.

37. Lu Q, Yang J, Liu Z, et al. Nebulized ceftazidime and amikacin in ventilator-associated pneumonia caused by Pseudomonas aeruginosa. Am J Respir Crit Care Med 2011;184(1):106-15.

38. Michalopoulos A, Papadakis E. Inhaled anti-infective agents: emphasis on colistin. Infection 2010;38(2): 81-8.

39. Palmer LB, Smaldone GC, Simon SR, et al. Aerosolized antibiotics in mechanically ventilated patients: delivery and response. Crit Care Med 1998;26(1): 31-9.

40. Goldstein I, Wallet F, Nicolas-Robin A, et al. Lung deposition and efficiency of nebulized amikacin during Escherichia coli pneumonia in ventilated piglets. Am J Respir Crit Care Med 2002;166(10):1375-81.

41. Palmer LB, Smaldone GC, Chen JJ, et al. Aerosolized antibiotics and ventilator-associated tracheobronchitis in the intensive care unit. Crit Care Med 2008;36(7):2008-13.

42. Palmer LB, Smaldone GC. Reduction of bacterial resistance with inhaled antibiotics in the intensive 
care unit. Am J Respir Crit Care Med 2014;189(10): 1225-33.

43. Feeley TW, Du Moulin GC, Hedley-Whyte J, et al. Aerosol polymyxin and pneumonia in seriously ill patients. N Engl J Med 1975;293(10):471-5.

44. Chastre J, Wolff M, Fagon J-Y, et al. Comparison of 8 vs 15 days of antibiotic therapy for ventilatorassociated pneumonia in adults: a randomized trial. JAMA 2003;290(19):2588-98.

45. Luyt C-E, Bréchot N, Trouillet J-L, et al. Antibiotic stewardship in the intensive care unit. Crit Care 2014;18(5):480.

46. Goldstein I, Wallet F, Robert J, et al. Lung tissue concentrations of nebulized amikacin during mechanical ventilation in piglets with healthy lungs. Am J Respir Crit Care Med 2002;165(2):171-5.

47. Lu Q, Girardi C, Zhang M, et al. Nebulized and intravenous colistin in experimental pneumonia caused by Pseudomonas aeruginosa. Intensive Care Med 2010;36(7):1147-55.

48. Le Conte P, Potel G, Peltier P, et al. Lung distribution and pharmacokinetics of aerosolized tobramycin. Am Rev Respir Dis 1993;147(5):1279-82.

49. Niederman MS, Chastre J, Corkery K, et al. BAY41-6551 achieves bactericidal tracheal aspirate amikacin concentrations in mechanically ventilated patients with Gram-negative pneumonia. Intensive Care Med 2012;38(2):263-71.

50. Athanassa ZE, Markantonis SL, Fousteri M-ZF, et al. Pharmacokinetics of inhaled colistimethate sodium (CMS) in mechanically ventilated critically ill patients. Intensive Care Med 2012;38(11): 1779-86.

51. Boisson M, Jacobs M, Grégoire N, et al. Comparison of intrapulmonary and systemic pharmacokinetics of colistin methanesulfonate (CMS) and colistin after aerosol delivery and intravenous administration of CMS in critically ill patients. Antimicrob Agents Chemother 2014;58(12):7331-9.

52. Czosnowski QA, Wood GC, Magnotti LJ, et al. Adjunctive aerosolized antibiotics for treatment of ventilator-associated pneumonia. Pharmacotherapy 2009;29(9):1054-60.

53. Rattanaumpawan $P$, Lorsutthitham J, Ungprasert P, et al. Randomized controlled trial of nebulized colistimethate sodium as adjunctive therapy of ventilator-associated pneumonia caused by Gramnegative bacteria. J Antimicrob Chemother 2010; 65(12):2645-9.

54. Kollef MH, Ricard J-D, Roux D, et al. A randomized trial of the amikacin fosfomycin inhalation system for the adjunctive therapy of gram-negative ventilatorassociated pneumonia: IASIS trial. Chest 2017; 151(6):1239-46.

55. Solé-Lleonart C, Rouby J-J, Blot S, et al. Nebulization of antiinfective agents in invasively mechanically ventilated adults: a systematic review and metaanalysis. Anesthesiology 2017;126(5):890-908.

56. Rello J, Solé-Lleonart C, Rouby J-J, et al. Use of nebulized antimicrobials for the treatment of respiratory infections in invasively mechanically ventilated adults: a position paper from the European Society of Clinical Microbiology and Infectious Diseases. Clin Microbiol Infect 2017;23(9):629-39.

57. Russell CJ, Shiroishi MS, Siantz E, et al. The use of inhaled antibiotic therapy in the treatment of ventilator-associated pneumonia and tracheobronchitis: a systematic review. BMC Pulm Med 2016; $16: 40$.

58. Wood GC, Boucher BA, Croce MA, et al. Aerosolized ceftazidime for prevention of ventilatorassociated pneumonia and drug effects on the proinflammatory response in critically ill trauma patients. Pharmacotherapy 2002;22(8):972-82.

59. Poulakou G, Siakallis G, Tsiodras S, et al. Nebulized antibiotics in mechanically ventilated patients: roadmap and challenges. Expert Rev Anti Infect Ther 2017; 15(3):211-29.

60. Florescu DF, Qiu F, McCartan MA, et al. What is the efficacy and safety of colistin for the treatment of ventilator-associated pneumonia? A systematic review and meta-regression. Clin Infect Dis 2012; 54(5):670-80.

61. Chastre J, Fagon J-Y. Ventilator-associated pneumonia. Am J Respir Crit Care Med 2002;165(7): 867-903.

62. Karvouniaris M, Makris D, Zygoulis P, et al. Nebulised colistin for ventilator-associated pneumonia prevention. Eur Respir J 2015;46(6):1732-9.

63. Lu Q, Luo R, Bodin L, et al. Efficacy of high-dose nebulized colistin in ventilator-associated pneumonia caused by multidrug-resistant Pseudomonas aeruginosa and Acinetobacter baumannii. Anesthesiology 2012;117(6):1335-47.

64. Falagas ME, Agrafiotis M, Athanassa Z, et al. Administration of antibiotics via the respiratory tract as monotherapy for pneumonia. Expert Rev Anti Infect Ther 2008;6(4):447-52.

65. Michalopoulos A, Fotakis D, Virtzili S, et al. Aerosolized colistin as adjunctive treatment of ventilatorassociated pneumonia due to multidrug-resistant Gram-negative bacteria: a prospective study. Respir Med 2008;102(3):407-12.

66. Kwa ALH, Loh C, Low JGH, et al. Nebulized colistin in the treatment of pneumonia due to multidrugresistant Acinetobacter baumannii and Pseudomonas aeruginosa. Clin Infect Dis 2005;41(5):754-7.

67. Berlana D, Llop JM, Fort E, et al. Use of colistin in the treatment of multiple-drug-resistant gram-negative infections. Am J Health Syst Pharm 2005;62(1): 39-47.

68. Tumbarello M, De Pascale G, Trecarichi EM, et al. Effect of aerosolized colistin as adjunctive treatment 
on the outcomes of microbiologically documented ventilator-associated pneumonia caused by colistin-only susceptible gram-negative bacteria. Chest 2013;144(6):1768-75.

69. Zampieri FG, Nassar AP, Gusmao-Flores D, et al. Nebulized antibiotics for ventilator-associated pneumonia: a systematic review and meta-analysis. Crit Care 2015;19:150.

70. Liu D, Zhang J, Liu H-X, et al. Intravenous combined with aerosolised polymyxin versus intravenous polymyxin alone in the treatment of pneumonia caused by multidrug-resistant pathogens: a systematic review and meta-analysis. Int J Antimicrob Agents 2015;46(6):603-9.

71. Valachis A, Samonis G, Kofteridis DP. The role of aerosolized colistin in the treatment of ventilatorassociated pneumonia: a systematic review and metaanalysis. Crit Care Med 2015;43(3): 527-33.

72. Kalil AC, Metersky ML, Klompas M, et al. Management of adults with hospital-acquired and ventilator-associated pneumonia: 2016 clinical practice guidelines by the Infectious Diseases Society of America and the American Thoracic Society. Clin Infect Dis 2016;63(5):e61-111.

73. Nseir S, Martin-Loeches I, Makris D, et al. Impact of appropriate antimicrobial treatment on transition from ventilator-associated tracheobronchitis to ventilator-associated pneumonia. Crit Care 2014; 18(3):R129.

74. Lin C-C, Liu T-C, Kuo C-F, et al. Aerosolized colistin for the treatment of multidrug-resistant Acinetobacter baumannii pneumonia: experience in a tertiary care hospital in northern Taiwan. J Microbiol Immunol Infect 2010;43(4):323-31.

75. Athanassa ZE, Myrianthefs PM, Boutzouka EG, et al. Monotherapy with inhaled colistin for the treatment of patients with ventilator-associated tracheobronchitis due to polymyxin-only-susceptible Gramnegative bacteria. J Hosp Infect 2011;78(4):335-6.

76. Kofteridis DP, Alexopoulou C, Valachis A, et al. Aerosolized plus intravenous colistin versus intravenous colistin alone for the treatment of ventilatorassociated pneumonia: a matched case-control study. Clin Infect Dis 2010;51(11):1238-44.

77. Doshi NM, Cook CH, Mount KL, et al. Adjunctive aerosolized colistin for multi-drug resistant gramnegative pneumonia in the critically ill: a retrospective study. BMC Anesthesiol 2013;13(1):45.

78. Abdellatif S, Trifi A, Daly F, et al. Efficacy and toxicity of aerosolised colistin in ventilator-associated pneumonia: a prospective, randomised trial. Ann Intensive Care 2016;6(1):26. 